\title{
A regulação da Educação Infantil em Belo Horizonte ${ }^{1}$
}

\section{The regulation of Early Childhood Education in Belo Horizonte}

\author{
Mércia de Figueiredo Noronha Pinto ${ }^{2}$ \\ Adriana Maria Cancella Duarte ${ }^{2}$
}

\begin{abstract}
RESUMO
Este artigo apresenta uma pesquisa empírica dos processos de regulação e das lógicas de ação predominantes em uma Escola Municipal de Educação Infantil (EMEI) e em uma Unidade Municipal de Educação Infantil (UMEI) de Belo Horizonte. O estudo analisa o modo como as regras e as normas emanadas pela administração municipal são formuladas, traduzidas e aplicadas no contexto dessas escolas. Os resultados evidenciam a intercessão entre o controle e a autonomia, no que concerne à regulação institucional exercida pelo Estado e à regulação situacional definida por meio da ação das docentes; o que constitui o caráter multirregulado da política de Educação Infantil do município.
\end{abstract}

Palavras-chave: Educação Infantil; regulação; ação pública; descentralização; Belo Horizonte.

\begin{abstract}
This article presents an empirical research of the regulatory processes and logics of action prevalent in a Municipal School of Early Childhood Education (Escola Municipal de Educação Infantil - EMEI) and in a Municipal Unit of Early Childhood Education (Unidade Municipal de Educação Infantil - UMEI) of Belo Horizonte. The study examines how the rules and regulations issued by the municipal administration are formulated, translated
\end{abstract}

DOI: $10.1590 / 0104-4060.40996$

1 Pesquisa financiada por bolsa doutorado da Fundação de Amparo à Pesquisa de Minas Gerais, no período de 05/2012 a 07/2014.

2 Universidade Federal de Minas Gerais. Faculdade de Educação. Belo Horizonte, Minas Gerais, Brasil. Avenida Antônio Carlos, nº 6627 - Pampulha. CEP: 31.270-901. E-mails: mercia. noronha@terra.com.br; driduarte58@gmail.com 
and applied in the context of these schools. The results show the intercession between control and autonomy, regarding the institutional regulation by the State and the situational adjustment set through the action of teachers which define the multiple regulated character of the Early Childhood Education policy by the municipality.

Keywords: Early Childhood Education; regulation; public action; decentralization; Belo Horizonte.

\section{Introdução}

No âmbito da sociologia política e da ação pública, a política de Educação Infantil é compreendida no contexto de descentralização do sistema educacional brasileiro como uma ação pública multirregulada, que envolve múltiplos atores em diferentes níveis. Nessa perspectiva, a partir de pressupostos teóricos relacionados à ação pública, à regulação e à descentralização das políticas educacionais, aquela política é apreendida como um processo complexo, que não se restringe à ação do Estado e da sua regulação, mas que resulta da participação dos vários atores nesse processo.

Mobilizando esse referencial teórico, este texto apresenta um estudo empírico, no qual foi analisada a política de Educação Infantil do município de Belo Horizonte, considerando a reconfiguração do papel do Estado e o conjunto de diplomas legais produzido sobre essa matéria, em especial a Lei n ${ }^{\circ} 8.679 / 2003^{3}$, que implantou o Programa Primeira Escola na Rede Municipal de Educação de Belo Horizonte (RME/BH), e o Programa BH Metas e Resultados ${ }^{4}$, em vigor desde 2009. O estudo centrou-se na ação das docentes de uma EMEI e de uma UMEI, na expectativa de compreender os processos de regulação presentes no interior dessas escolas.

Este trabalho foi realizado à luz de um modelo interpretativo construído com base em quatro categorias: domínios, locais, modos e atores. Além disso, utilizou-se a análise de conteúdo de um extenso corpus documental concernente à observação e à pesquisa em documentos das escolas e às entrevistas com as docentes.

3 Lei $n^{\circ} 8.679$, de 11 de novembro de 2003. "Cria as Unidades Municipais de Educação Infantil e o cargo de Educador Infantil, altera as Leis n ${ }^{\circ}$ 7.235/96 e 7.577/98 e dá outras providências".

4 Decreto ${ }^{\circ}$ 13.568, de 13 de maio de 2009. "Institui a Gestão Estratégica Orientada por Resultados e cria o Programa BH Metas e Resultados". 
Os dados revelaram que a política de Educação Infantil em Belo Horizonte caracteriza-se pela tensão entre o controle da administração municipal sobre as escolas, diante da influência da regulação nacional e da regulação transnacional, e pelos modos de regulação autônoma, definidos pela ação das docentes em função dos seus saberes, experiência, interesses e estratégias.

O texto está organizado em três seções. Na primeira seção, far-se-á uma síntese sobre a abordagem das políticas de Educação Infantil concebidas como ação pública. Na segunda seção, são apresentados os modos de regulação das escolas, identificados a partir do estudo empírico, com base nas quatro categorias mencionadas. Na terceira seção, busca-se evidenciar a tensão entre os processos de regulação de controle e de regulação autônoma na EMEI e na UMEI. Por fim, são apresentadas as considerações finais.

\section{A abordagem das políticas de Educação Infantil como ação pública}

O estudo aborda as políticas públicas de Educação Infantil sob um entendimento alargado do conceito de política, compreendida como uma ação pública multirregulada, uma vez que a política pública não se resume à ação do Estado. Ou seja, não obstante o Estado permanecer com um papel proeminente na formulação e implementação das políticas, esse papel é compartilhado com outras entidades e atores. (BARROSO, 2006). De acordo com essa concepção, os Estados deixaram de ter um papel hegemônico na definição das políticas públicas, como a Educação Infantil, diante da multiplicidade de atores que intervém no funcionamento dessas políticas.

Nesse sentido, o emprego do termo ação pública marca uma mudança na perspectiva do campo de conhecimento das Ciências Sociais em que o Estado age em conjunto com uma pluralidade de atores públicos e privados, da sociedade civil, na variedade de interdependências em nível nacional, local e supranacional para produzir formas de regulação de atividades coletivas. (COMMAILLE, 2004).

Segundo Delvaux (2007), a ação pública pode ser caracterizada em seis dimensões principais, mas intimamente relacionadas: multiplicidade e diversidade de atores; característica compósita do ator público; diminuição das relações hierárquicas entre os atores; relativização do impacto do momento de tomada de decisão política; não linearidade dos processos; fragmentação e flexibilização da ação pública. 
Esse ponto de vista remete a um contexto de transformações do papel do Estado e de um novo modo de intervenção governativa muito mais complexo, em que a ação pública é regulada por meio da participação e das relações entre os vários atores. Nesse contexto de mudanças, assiste-se a uma transição progressiva de modos de regulação burocráticos, centrados na formalização de objetivos para a ação a priori, para outros modos de regulação, designados de pós-burocráticos, centrados preferencialmente nos resultados obtidos a posteriori. (MAROY, 2005).

Simultaneamente observa-se a autonomia de outros atores (por exemplo, as escolas) para se apropriar das regras produzidas e aplicadas pela autoridade, ou até mesmo para propor ações (regulação situacional ou autônoma), respectivamente ao papel do Estado de produzir e aplicar as regras que coordenam e orientam esses atores (regulação institucional ou de controle).

Nessa perspectiva, a política de Educação Infantil em Belo Horizonte foi examinada com o objetivo de ilustrar modos de regulação para além da regulação de controle, considerando especificamente a regulação das escolas diante da combinação dos interesses, das negociações e das ações realizadas pelas docentes, perante as normas e injunções determinadas pela administração municipal.

Analisar os processos de regulação das escolas significa atribuir importância às estratégias de aplicação e produção de regras e normas pelos atores inseridos nos diversos espaços e tempos de construção da política e também aos conflitos e negociações entre esses mesmos atores. Isto implica, portanto, considerar a interação entre as lógicas de produção e de decisão política e as lógicas de apropriação dessa mesma decisão.

\section{Os processos de regulação na EMEI e na UMEI: domínios, locais, modos e atores}

Em Belo Horizonte, a intervenção do Estado no campo da educação nos últimos anos tem se efetuado por meio de políticas educacionais que consagram um modelo de gestão sustentado em medidas de descentralização e de reforço da autonomia das escolas. Essas políticas se inserem nos processos de recomposição do papel do Estado na administração da ação pública e nas suas formas de governo, bem como corroboram a influência que as instâncias nacionais e internacionais exercem no sentido da convergência das políticas e dos modos de regulação da educação. A legislação em vigor - Constituição Federal de 1988, Lei de Diretrizes e Bases da Educação Nacional (LDB - Lei no 9.394/96), 
Lei Orgânica do Município de Belo Horizonte de 1990 - estabelece a gestão democrática do ensino público, com incentivo à participação da comunidade no processo educacional e o fortalecimento da responsabilização local.

Assim, a legislação prevê que as escolas disponham de autonomia, por meio dos seus órgãos representativos em função das suas competências, em determinados domínios: pedagógico (elaboração da proposta pedagógica), administrativo (a escola como lugar central de gestão das condições materiais, físicas e humanas) e financeiro (gerenciamento dos recursos financeiros).

No que tange a esses domínios, os dados recolhidos na pesquisa permitiram verificar que, no processo de regulação, as escolas possuem maior margem de autonomia em relação às questões pedagógicas e menor em relação às questões administrativas e financeiras. Como se constatou, as escolas estudadas possuem espaços formais ou até mesmo não instituídos para construírem autonomia diante da regulação exercida pela administração educacional, a partir das estratégias e lógicas de ação das docentes.

Barroso (2005c) chama a atenção para o fato de a autonomia da escola ser sempre relativa, uma vez que esta se exerce por meio de atribuições, competências e recursos transferidos ou delegados de outros níveis da administração, assim como se desenvolve em um contexto de múltiplas dependências, pela interação entre o governo, os professores, os alunos e as suas famílias. É, portanto, um processo de construção social e política, resultado da ação dos indivíduos que compõem a escola.

No domínio pedagógico, as docentes da Educação Infantil identificam processos de relativa autonomia diante da possibilidade de fazerem escolhas e tomarem decisões em seu cotidiano de trabalho, a partir dos saberes profissionais, da experiência docente, das necessidades das crianças, das demandas dos pais, do modo como é feita a coordenação pedagógica e da forma como traduzem as diretrizes definidas pela Secretaria Municipal de Educação (SMED) em relação à implementação das Proposições Curriculares do município e à elaboração da proposta pedagógica. A ação educacional, nesse caso, caracteriza-se como uma regra do jogo, a que se refere Reynaud (2003).

Tenho essa liberdade na prefeitura, que a gente brinca que a gente não pode confundir com libertinagem, porque na escola particular, às vezes, você tem tudo muito marcadinho, "faça isso, faça aquilo" dessa maneira. Na prefeitura, você tem o suporte das linguagens e ai não tem uma pessoa para ficar, digamos assim, vigiando o seu trabalho diariamente, você fez, você não fez, você gastou seu tempo de que maneira? A pessoa tem que se policiar para não deixar a coisa correr solta demais, não amarrar 
e não dar uma orientação para o trabalho. (PROFESSORA 2, UMEI. Entrevista concedida às autoras. Belo Horizonte, $1^{\circ}$ novembro 2012).

Essa relativa autonomia das docentes é condicionada por aspectos organizacionais das escolas que compreendem a ação dos funcionários não docentes, a divisão do trabalho, as relações (internas e externas), a gestão do tempo e do espaço, a rotina das crianças, a realização das atividades, a estrutura física e as condições de trabalho (número de crianças nas salas, número de professoras nas escolas, absenteísmo, jornada e sobrecarga de trabalho).

A quantidade de alunos por sala, eu acho que isso é uma grande questão. Esse sempre vai ser o meu questionamento. São muitos alunos, são muitas demandas, então são muitas famílias, são muitas questões e a gente é uma só para poder dar conta de tudo. Então, a quantidade de crianças, eu acho que é a minha maior dificuldade. (PROFESSORA 6, EMEI. Entrevista concedida às autoras. Belo Horizonte, $1^{\circ}$ outubro 2012).

No que tange aos domínios administrativo e financeiro, observa-se que a ação reguladora da Prefeitura de Belo Horizonte $(\mathrm{PBH})$ sobre as escolas se faz de forma mais incisiva e constrangedora, de modo a assegurar o cumprimento da política educacional do município. Nesse sentido, as medidas de descentralização e de autonomia, que caracterizam a escola como o lugar central da gestão, paradoxalmente implicam na centralização dos espaços de planejamento e na intensificação dos mecanismos de controle pelo governo.

Segundo Barroso (2005a), se, do ponto de vista retórico, as políticas de reforço da autonomia aumentaram o poder de decisão e os recursos para as escolas e, simultaneamente, maior responsabilização e participação de todos os agentes educativos, assiste-se, na prática, e de maneira contraditória, ao alargamento dos processos de controle, externo e interno, da organização educativa, inibidores de uma efetiva autonomia.

Cribb e Gewirtz (2007) ressaltam a distinção entre os agentes individuais (professores, pais, estudantes, entre outros), os agentes coletivos (sindicato dos professores, associação de pais e estudantes, etc.) e os agentes institucionais (escolas, órgãos do governo, etc.) que fazem parte da arena educacional, já que, para eles, o aumento da autonomia de um desses agentes, com frequência, faz diminuir a autonomia do outro. Assim, entende-se que as medidas que visam ampliar a autonomia das escolas, incoerentemente, podem enfraquecer a autonomia individual dos atores e, por consequência, aumentar o controle sobre eles. 
Nas escolas estudadas, o controle administrativo e financeiro é exercido, nomeadamente, sobre a direção das escolas, como pode ser percebido no relato da diretora da EMEI:

Acho que tem um nivel altíssimo de expectativa, porque coloca uma carga muito grande nos ombros de quem é diretor da escola, com pouca autonomia. É um trabalho muito engessado que não pode, por exemplo, contratar pessoal sem seguir uma série de critérios, você não pode demitir sem o aval da Secretaria. Eu acho até importante, que é uma segurança que você tem, mas é um trabalho muito engessado, é muito amarrado. Mas, o nivel de expectativa da Secretaria é muito grande de quem está na direção, inclusive, de repente, de ter até superpoderes, porque é uma carga muito, muito grande. (DIRETORA. Entrevista concedida às autoras. Belo Horizonte, $1^{\circ}$ novembro 2012).

Dentre a diversidade de atores locais que intervém nas escolas (direção, professoras, SMED, funcionários, crianças, pais, comunidade) e que resulta em múltiplas regulações (externa/controle e interna/controle + autonomia), as diretoras desempenham um papel relevante na tomada de decisão, pois influenciam a maior parte das decisões concernentes à organização e funcionamento das escolas e são a referência no processo de tradução das normas externas e de produção das normas internas. Essa liderança decorre, de maneira geral, das mudanças nos modos de regulação da educação e dos novos instrumentos da ação pública, conferindo proeminência à figura da direção, que se vê envolvida em lógicas de ação referentes aos objetivos de melhoria da qualidade da educação. Verifica-se, portanto, que, embora estejam sujeitas ao controle externo, as diretoras também têm o potencial para exercerem o controle interno.

No novo modelo de administração municipal e de redefinição do papel do Estado como regulador da ação pública, sob a influência da nova gestão pública (new public management), observa-se a introdução de instrumentos de controle mais formalizados e publicizados. Esses instrumentos, investidos de maior relevância e eficácia, possibilitam materializar, operacionalizar e legitimar as decisões políticas, uma vez que orientam o comportamento dos atores, responsabilizam diretamente as escolas pela qualidade da educação e evidenciam os resultados da ação pública. Permitem também colocar em relevo o jogo dos atores, as representações da política nas escolas e, portanto, os processos de multirregulação da educação.

Especialmente na Educação Infantil, as orientações municipais que regulam a política educacional são veiculadas por uma variedade de instrumentos 
em relação à gestão escolar, à gestão do trabalho e à carreira das docentes e ao preenchimento de vagas. Nesse sentido, impõem um conjunto de medidas de controle que tem implicações na regulação das escolas e na produção de estratégias e lógicas que orientam a ação dos atores.

[...] a diretora fez um plano de ação depois que ela passou pelo processo de eleição. Então, ela tem um plano. Nos três anos que vai ficar na escola, quais as metas que ela quer. É tudo muito orientado, a gente tem que seguir. A Prefeitura já tem tudo pronto. Tem o plano de ação que a acompanhante pedagógica faz também. Ela cria um plano de ação em cada escola que ela trabalha. É um documento com as propostas a serem feitas no decorrer do ano. Então, ela estabelece as metas para o ano. Ela vê quais são as necessidades da escola que ela vem acompanhando e dentro desse documento ela vai colocando as metas que têm que ser cumpridas, o que éque falta na escola ou o que precisa melhorar, o que deve ser criado, qual é a modificação que precisa ser feita e vem trabalhando com a gente para ir mudando, ou para construir alguma coisa e ela vem direcionando. Então, esse documento fala disso tudo. (COORDENADORA EMEI. Entrevista concedida às autoras. Belo Horizonte, 09 novembro 2012).

A organização do trabalho nas escolas é visivelmente influenciada pela regulação de controle da $\mathrm{PBH}$ por meio de normas e de vários instrumentos, mas também pelo modo como é realizada a regulação autônoma, a partir das possibilidades de ação dos atores locais no desenvolvimento das suas atividades.

No processo de regulação, as escolas passam a contar com espaços formais de autonomia, por meio da participação de outros atores da sociedade e da comunidade na sua gestão. Essas medidas que integram um conjunto de mudanças nos modos de governar a educação dizem respeito às políticas de descentralização e de aumento do poder de decisão dos órgãos de gestão das escolas. Nesse caso, a autonomia das escolas se dá com a diminuição da dependência vertical em relação à administração e, consequentemente, com o aumento das interdependências horizontais com a comunidade local. Efetivamente, essas instâncias têm possibilitado a circulação das informações, o confronto dos pontos de vista dos vários atores e a análise das ações das diretoras.

Têm momentos de reuniões, as assembleias, o colegiado, que são os momentos onde são tomadas as decisões da escola, que é necessária a presença da comunidade e das professoras também. Então a gente tem 
esses momentos coletivos [...]. (PROFESSORA 6, EMEI. Entrevista concedida às autoras. Belo Horizonte, $1^{\circ}$ outubro 2012).

É a partir da caracterização da regulação das escolas que se identificam a atuação das docentes e as lógicas de ação dominantes, bem como as possibilidades de construção de processos de regulação autônoma diante da regulação externa exercida pelo governo e, ainda, os espaços de autonomia que ampliam o controle interno.

Para além dos órgãos de gestão instituídos nas escolas, que dizem da autonomia e do controle interno, o relato abaixo ilustra modos de regulação que demonstram margens de autonomia docente e produção de regras próprias em relação à organização e à realização do trabalho. Esse espaço de manobra dá visibilidade ao papel dos atores individuais na ação pública e deixa transparecer os processos de regulação autônoma:

No fim do ano, quando a gente faz uma reunião para reorganizar o grupo para o próximo ano, da escolha de turmas, acontece também uma avaliação do trabalho, do grupo todo, do que pode ser melhorado, do que não deu certo, do que a gente pode avançar para o ano que vem. Ai, quem está na direção, na coordenação, sempre anota os pontos que foram abordados e essas sugestões para o próximo ano, porque, no começo do ano, a gente sempre tem uma folh a com orientações e aí a gente percebe que essas sugestões que foram feitas lá na reunião de encerramento, elas vêm na folha de sugestões de começo do ano, na organização do seu trabalho. (PROFESSORA2, UMEI. Entrevista concedida às autoras. Belo Horizonte, $1^{\circ}$ novembro 2012).

Assim, a complexidade das escolas cria novos espaços de ação estratégica dos vários intervenientes, diante da forma como reagem à regulação de controle e potencializam processos de regulação autônoma.

Como afirma Lima (2011):

A escola não é apenas uma instância hetero-organizada para a reprodução, mas é também uma instância auto-organizada para a produção de orientações e de regras, expressão das capacidades estratégicas dos atores e do exercício (político) de margens de autonomia relativa, o que lhes permite, umas vezes, retirar benefícios da centralização e, outras vezes, colher vantagens de iniciativas que a afrontam. (LIMA, 2011, p. 115). 
As escolas são locais de multirregulação, onde as normas e regras que asseguram o seu funcionamento são resultado de um processo compósito de produção em que se confrontam, negociam-se, conciliam-se ou se sobrepõem princípios, interesses, estratégias e lógicas de ação distintos. (BARROSO et al., 2004).

Em síntese, o modo como é realizada a regulação das escolas em ambos os casos estudados decorre dos interesses em jogo e das estratégias de intervenção dos diferentes atores implicados nesse processo. Nomeadamente, é bastante influenciado pela ação das docentes, pela forma como estas interpretam e se apropriam das normas, transformando os efeitos da regulação institucional e de controle.

\section{A tensão entre os processos de regulação de controle e de regulação autônoma nas escolas e a emergência de "eventual" regulação compósita}

Como se viu pela apresentação e discussão dos dados concernentes às categorias de análise (domínios, locais, modos e atores), coexistem nas escolas processos de regulação de controle e de regulação autônoma que resultam das estratégias, interesses e interações entre os atores. Há sempre uma adaptação e interpretação local das normas e das regras diante da possibilidade de as docentes alterarem ou mesmo decidirem sobre as questões próprias do seu trabalho, no uso das suas margens de autonomia relativa.

A descrição e a análise efetuadas das formas de apropriação das normas pelas docentes permitem pôr em evidência alguns elementos que condicionam os processos de regulação na EMEI e na UMEI e também as lógicas de ação que emergem dos seus processos e efeitos:

- A importância e o conhecimento especializado das docentes definem uma regulação autônoma e fazem com que elas exerçam maior influência no processo decisório, quer na capacidade de adaptar e transformar as normas e os dispositivos externos da regulação de controle, quer na possibilidade de produzir regras próprias. As professoras dispõem de espaços de relativa autonomia, individual e coletiva, no desempenho das atividades pedagógicas. Nesse caso, elas demonstraram ter uma margem maior de proposição, atuação, decisão e adequação do planejamento à realidade da turma e à faixa etária das crianças. Elas também deixaram transparecer como traduzem e utilizam as Proposições Curriculares do município na ação educativa e como 
participam da elaboração da proposta pedagógica, tendo em vista as orientações da SMED, mas caracterizando um processo autônomo e específico, de acordo com a realidade atual de cada uma das escolas. Assim, pode-se também inferir que a prática pedagógica resulta em uma combinação entre os processos de regulação institucional e situacional, tendo em vista a produção de regras comuns, de modo a coordenar a ação coletiva nas escolas, a que Barroso (2005b), no segmento de Reynaud (2003), chamou de "regulação conjunta";

- As diretoras têm um papel relevante na organização do trabalho nas escolas, pois, ainda que estejam mais sujeitas ao controle externo, elas também exercem o controle interno. Isso quer dizer que se pode falar em autonomia relativa das professoras considerando que ela é limitada não só pela regulação do Estado, mas também pelas ações de outras docentes, que na unidade escolar se encontram em funções de gestão;

- Essa relativa autonomia das docentes é condicionada por aspectos organizacionais das escolas e pelas condições de trabalho das docentes;

- A importância do colegiado escolar e da assembleia escolar no processo de regulação das escolas, por serem espaços que permitem ações mais horizontalizadas com a participação dos pais e da comunidade na gestão escolar e que favorecem a autonomia e o controle social. Efetivamente, essas instâncias têm propiciado a circulação das informações e o confronto dos pontos de vista dos vários atores no âmbito das escolas;

- A relação com as famílias, tendo em vista a especificidade das crianças nessa faixa etária. Nesse sentido, foi possível perceber o modo como os pais interferem nos processos de regulação das escolas;

- O controle da PBH e da SMED de maneira mais incisiva sobre os domínios administrativo e financeiro das escolas, apresentado em diversos instrumentos da ação pública. A diversidade e a proeminência dos instrumentos de controle, nomeadamente sobre a direção das escolas, visam à administração e prestação de contas dos recursos financeiros, à implementação da política educacional do município e à qualidade da educação. Nesse contexto, observou-se a valorização crescente da avaliação de desempenho das docentes;

- A regulação da administração municipal sobre a oferta e a demanda de vagas, o que implicou na criação de um sistema informatizado de controle de matrícula das crianças nas instituições de Educação Infantil da RME/BH. Esse controle estatal repercute na quantidade de crianças por turma e nos modos como as docentes realizam o trabalho nas escolas. 
A regulação das escolas acarreta uma tensão aparentemente contraditória entre a regulação de controle da administração municipal e os modos de regulação autônoma definidos pela forma como as docentes agem em função das demandas, dos seus saberes, interesses e estratégias, mas que constitui a complexidade da política de Educação Infantil.

Isso significa que o Estado deve promover a articulação entre as esferas do sistema educacional: assumindo as responsabilidades que lhe são inerentes e assegurando as condições necessárias (físicas, materiais, de pessoal, de trabalho, de financiamento, etc.) para o funcionamento das escolas e para a edificação da autonomia. Como afirma Barroso (2005c), o reforço da autonomia das escolas exige que seja preservado e aumentado o papel regulador do Estado e da sua administração, com o fim de evitar a segmentação e a pulverização dos sistemas de ensino, bem como de garantir a democratização do seu funcionamento e a equidade do serviço prestado.

Nesse sentido, Cribb e Gewirtz (2007) assinalam a importância do equilíbrio entre autonomia e controle, apresentando argumentos a favor da autonomia individual do professor e argumentos a favor do controle do Estado, os quais ilustram o equívoco com qualquer suposição geral de que a autonomia do professor é sempre uma coisa boa e que limitá-la é sempre ruim. Além disso, esses autores ressaltam que a relação entre autonomia e controle não é de forma alguma simples e em particular não deveria ser vista como um jogo de soma zero, isto é, como se o aumento do controle fosse necessariamente inversamente proporcional à diminuição da autonomia ou vice-versa. Para eles, os professores precisam tanto de autonomia quanto de controle e o que deve ser discutido é o equilíbrio entre esses dois conceitos intimamente ligados e as diferentes formas por meio das quais eles podem ser combinados.

$\mathrm{Na}$ investigação, pôde ser constatado que a regulação da administração municipal por meio do estabelecimento de critérios para o preenchimento de vagas, da definição do currículo e da implementação de programas educacionais se justifica para assegurar o direito das crianças às políticas públicas voltadas à infância, à oportunidade de acesso à Educação Infantil e a uma experiência educacional comum. Entretanto, a quantidade de instrumentos concernentes às políticas educativas dificulta o fortalecimento da gestão democrática nas escolas, já que orienta a ação dos atores, preconizando metas de eficiência e qualidade e a lógica de resultados.

Da mesma forma, como foi mostrado, as professoras, como intervenientes privilegiadas no processo de regulação das escolas, dispõem de relativa autonomia no desenvolvimento da prática pedagógica, pelo modo como exercem as competências que lhes são atribuídas, buscando adequar as normas e as regras ao contexto local; o que indica a coexistência e a sobreposição de múltiplos processos de regulação. 


\section{Considerações finais}

Dos dados apresentados e discutidos em função de cada categoria de análise (domínios, locais, modos e atores), foi possível extrair alguns pontos centrais para a compreensão dos processos de regulação das escolas que, embora não sejam definitivos, representam a passagem da descrição para a inferência.

Em primeiro lugar, estudar a política de Educação Infantil do município de Belo Horizonte como ação pública implica prestar atenção à multiplicidade de atores envolvidos nesse processo. $\mathrm{O}$ estudo permitiu dar visibilidade aos diferentes atores, individuais e coletivos, que exercem a regulação sobre as escolas estudadas, em função dos seus interesses e da capacidade de intervenção e que, por conseguinte, influenciam e constroem a política de Educação Infantil em Belo Horizonte: equipes da SMED, Conselho Municipal de Educação, assembleia escolar, colegiado escolar, direção, professoras, pais, crianças, funcionários, comunidade. Dentre esses atores, a investigação centrou-se sobre a ação das docentes, já que estas têm maior influência na regulação das escolas, pelo conhecimento e pelo poder de decisão em relação às normas e aos mecanismos da regulação de controle, bem como pela possibilidade de definirem uma regulação autônoma.

O trabalho empírico mostrou ainda a emergência de modos de regulação pós-burocráticos com o uso de diversos instrumentos pelo Estado, para além da produção legal, que intercedem na relação entre o governo e as escolas. Esses instrumentos incidem claramente sobre a gestão escolar e sobre as condições de trabalho e a carreira profissional das docentes. Associada a essa mudança, os dados também revelaram uma contradição nos objetivos da regulação, uma vez que, junto à adoção de medidas que visam à autonomia das escolas por meio do aumento do poder de decisão dos seus órgãos de gestão, da transferência de atribuições e de recursos e da construção da proposta pedagógica, a administração municipal exerce o controle sobre as escolas e as professoras com a introdução de processos de gestão relacionados à elaboração de planos de ação para identificar as prioridades a serem desenvolvidas, ao cumprimento de metas, ao controle da qualidade, entre outros.

Em segundo lugar, estudar a política de Educação Infantil do município de Belo Horizonte como uma ação pública multirregulada significa considerar a existência de modos de regulação de controle e de regulação autônoma. Nesse contexto de análise, a política de Educação Infantil resulta do confronto e de uma tensão permanente entre o controle exercido pela administração municipal e os espaços de autonomia experimentados pelas escolas e pelas docentes. A 
ação reguladora do governo sobre as escolas se faz, de maneira incongruente, nos domínios pedagógico, administrativo e financeiro. A percepção que as docentes têm da regulação é que ela se exerce, de forma mais constrangedora, nos domínios administrativo e financeiro, especialmente sobre a direção das escolas, no que tange, por exemplo, à administração e prestação de contas dos recursos financeiros e à implantação dos programas e políticas municipais. Em relação ao domínio pedagógico, a regulação é praticada, sobretudo, por meio da definição e aplicação das Proposições Curriculares do município, da elaboração (ou reformulação) pela escola da proposta pedagógica e do modo como é feita a coordenação pedagógica. Nesse aspecto, os depoimentos levam a entender que há uma margem para a autonomia das docentes quanto à realização das atividades pedagógicas. As lógicas de ação diante das necessidades das crianças, das demandas dos pais e da forma como traduzem as Proposições Curriculares e participam da construção da proposta pedagógica foram interpretadas como sinais de relativa autonomia, que potencializam os processos de regulação autônoma e uma eventual regulação compósita. Conforme se pôde notar, a autonomia relativa das docentes é limitada também pelo controle da direção e por fatores organizacionais das escolas.

Nesse sentido, os dados obtidos na pesquisa suscitam reflexões no que concerne a essa relativa autonomia docente, que acontece, sobretudo, no âmbito pedagógico, mas ainda de forma muito individualizada, diante da dificuldade ou mesmo da ausência de espaços e de tempo para a realização do trabalho coletivo e colaborativo. Há que destacar que essa situação pode ser considerada como um fator que restringe a capacidade de intervenção desses atores no processo político e na produção de regras comuns e de decisões coletivas que constituem uma regulação conjunta.

As análises realizadas ilustram o processo dialético e contraditório da regulação, levando em conta que não existe uma simples dicotomia entre a autonomia das escolas e o controle do Estado. Desse processo, fazem parte os constrangimentos e as tensões, o confronto de interesses, as resistências e, também, as negociações e as convergências entre os diversos atores.

De acordo com esse ponto de vista, a autonomia será sempre relativa e se efetivará com mais consistência no âmbito das escolas se existirem regras pactuadas coletivamente entre as diversas instâncias do sistema, com o envolvimento dos principais profissionais implicados no processo educativo, considerando as práticas vivenciadas no desenvolvimento das suas ações. (CABRAL NETO, 2012).

Em síntese, o estudo da política de Educação Infantil, em uma perspectiva de ação pública, permitiu apreender as estratégias de ação das docentes nas escolas, em presença das medidas prescritas pelo governo, no quadro de 
implantação de um modelo de gestão gerencial, configurando um objeto de análise complexo e híbrido.

Como ficou constatado, por um lado, o Estado procura exercer o papel que lhe é inerente de regulador da política educacional com a adoção dos dispositivos de controle; por outro lado, as docentes percebem a possibilidade de fazerem escolhas e decidirem quanto à realização do trabalho pedagógico, em função dos seus saberes, experiência, interesses e estratégias, tendo em vista uma prática mais apropriada à realidade de cada uma das escolas. Os resultados da investigação evidenciam a intercessão entre o controle e a autonomia, o que caracteriza a multirregulação da política de Educação Infantil em Belo Horizonte.

\section{REFERÊNCIAS}

BARROSO, J. Liderazgo y autonomía de los centros educativos. Revista Española de Pedagogía, Madrid, n. 232, p. 423-441, sep./dic. 2005a.

BARROSO, J. O Estado, a educação e a regulação das políticas públicas. Educação \& Sociedade, Campinas, v. 26, n. 92, p. 725-751, out. 2005b.

BARROSO, J. Políticas educativas e organização escolar. Lisboa: Universidade Aberta, 2005c.

BARROSO, J. A investigação sobre a regulação das políticas públicas de educação em Portugal. In: BARROSO, J. (Org.). A regulação das políticas públicas de educação: espaços, dinâmicas e actores. Lisboa: Educa, 2006. p. 9-39.

BARROSO, J. et al. Regulação interna e lógicas de acção nas escolas: dois estudos de caso em Portugal. Projecto REGULEDUCNETWORK - WP 9. Centro de Estudos da Escola, Faculdade de Psicologia e de Ciências da Educação, Universidade de Lisboa, 2004.

BELO HORIZONTE. Lei Orgânica do Municipio de Belo Horizonte. Belo Horizonte: Câmara Municipal, 1990.

BELO HORIZONTE. Lei $\mathrm{n}^{\circ} 8.679$, de 11 nov. 2003. Cria as Unidades Municipais de Educação Infantil e o cargo de Educador Infantil, altera as leis nº 7.235/96 e 7.577/98 e dá outras providências. Diário Oficial do Município, Belo Horizonte, 2003.

BELO HORIZONTE. Decreto $n^{\circ}$ 13.568, de 13 maio 2009. Institui a Gestão Estratégica Orientada por Resultados e cria o Programa BH Metas e Resultados. Diário Oficial do Município, Belo Horizonte, 2009. Disponível em: <www.pbh.gov.br>. Acesso em: 08 jun. 2012.

BRASIL. Constituição (1988). Constituição da República Federativa do Brasil. Brasília, 1988. Disponível em: <www.planalto.gov.br>. Acesso em: 21 jan. 2012. 
BRASIL. Lei no 9.394, de 20 dez. 1996. Lei de Diretrizes e Bases da Educação Nacional. Brasília, 1996. Disponível em: <www.planalto.gov.br>. Acesso em: 05 maio 2013.

CABRAL NETO, A. Gestão democrática: um estudo em escolas de educação básica no Brasil. In: OLIVEIRA, D. A.; VIEIRA, L. M. F. (Orgs.). Trabalho na educação básica: a condição docente em sete estados brasileiros. Belo Horizonte: Fino Traço, 2012. p. 257-284.

COMMAILLE, J. Sociologie de l'action publique. In: BOUSSAGUET, L.; JACQUOT, S.; RAVINET, P. (Dir.). Dictionnaire des politiques publiques. Paris: Sciences-Po Les Presses, 2004. p. 413-421.

CRIBB, A.; GEWIRTZ, S. Unpacking autonomy and control in education: some conceptual and normative groundwork for a comparative analysis. European Educational Research Journal, v. 6, n. 4, p. 203-213, 2007. Disponível em: <http://dx.doi.org/10.2304/ eerj.2007.6.3.203>. Acesso em: 18 maio 2013.

DELVAUX, B. L'action publique, ou analyser la complexité. Revue de la littérature. Know $\&$ Pol. Knowledge and Policy in education and health sectors. Juin. 2007. Disponível em: <www.knowandpol.eu>. Acesso em: 20 fev. 2013.

LIMA, L. C. A escola como organização educativa. 4. ed. São Paulo: Cortez, 2011.

MAROY, C. Une comparaison des formes de régulation intermédiaire dans cinq pays européens. In: DUTERCQ, Y. Les régulations des politiques d'éducation. Rennes: Presses Universitaires de Rennes, 2005.

REYNAUD, J.-D. Régulation de contrôle, régulation autonome, régulation conjointe. In: TERSSAC, G. (Dir.). La théorie de la régulation sociale de Jean Daniel-Reynaud: debats et prolongemeents. Paris: La Découverte, 2003. p. 11-33.

Texto recebido em 21 de abril de 2015. Texto aprovado em 25 de agosto de 2015. 